\title{
Article \\ NKL Homeobox Genes NKX2-3 and NKX2-4 Deregulate Megakaryocytic-Erythroid Cell Differentiation in AML
}

\author{
Stefan Nagel *, Claudia Pommerenke (D, Corinna Meyer and Roderick A. F. MacLeod
}

check for updates

Citation: Nagel, S.; Pommerenke, C.; Meyer, C.; MacLeod, R.A.F. NKL Homeobox Genes NKX2-3 and NKX2-4 Deregulate MegakaryocyticErythroid Cell Differentiation in AML. Int. J. Mol. Sci. 2021, 22, 11434. https://doi.org/10.3390/ijms222111434

Academic Editor: Amelia Casamassimi

Received: 24 September 2021

Accepted: 18 October 2021

Published: 22 October 202

Publisher's Note: MDPI stays neutral with regard to jurisdictional claims in published maps and institutional affiliations.

Copyright: (c) 2021 by the authors. Licensee MDPI, Basel, Switzerland. This article is an open access article distributed under the terms and conditions of the Creative Commons Attribution (CC BY) license (https:/ / creativecommons.org/licenses/by/ $4.0 /)$.
Department of Human and Animal Cell Lines, Leibniz-Institute DSMZ, German Collection of Microorganisms and Cell Cultures, 38124 Braunschweig, Germany; cpo14@dsmz.de (C.P.); cme@dsmz.de (C.M.); rafmacleod@gmail.com (R.A.F.M.)

* Correspondence: sna@dsmz.de; Tel.: +49-531-2616167

\begin{abstract}
NKL homeobox genes encode transcription factors that impact normal development and hematopoietic malignancies if deregulated. Recently, we established an NKL-code that describes the physiological expression pattern of eleven NKL homeobox genes in the course of hematopoiesis, allowing evaluation of aberrantly activated NKL genes in leukemia/lymphoma. Here, we identify ectopic expression of NKL homeobox gene NKX2-4 in an erythroblastic acute myeloid leukemia (AML) cell line OCI-M2 and describe investigation of its activating factors and target genes. Comparative expression profiling data of AML cell lines revealed in OCI-M2 an aberrantly activated program for endothelial development including master factor ETV2 and the additional endothelial signature genes HEY1, IRF6, and SOX7. Corresponding siRNA-mediated knockdown experiments showed their role in activating NKX2-4 expression. Furthermore, the ETV2 locus at 19p13 was genomically amplified, possibly underlying its aberrant expression. Target gene analyses of NKX2-4 revealed activated ETV2, HEY1, and SIX5 and suppressed FLI1. Comparative expression profiling analysis of public datasets for AML patients and primary megakaryocyte-erythroid progenitor cells showed conspicuous similarities to NKX2-4 activating factors and the target genes we identified, supporting the clinical relevance of our findings and developmental disturbance by NKX2-4. Finally, identification and target gene analysis of aberrantly expressed NKX2-3 in AML patients and a megakaryoblastic AML cell line ELF-153 showed activation of FLI1, contrasting with OCI-M2. FLI1 encodes a master factor for myelopoiesis, driving megakaryocytic differentiation and suppressing erythroid differentiation, thus representing a basic developmental target of these homeo-oncogenes. Taken together, we have identified aberrantly activated NKL homeobox genes NKX2-3 and NKX2-4 in AML, deregulating genes involved in megakaryocytic and erythroid differentiation processes, and thereby contributing to the formation of specific AML subtypes.
\end{abstract}

Keywords: HOX-code; NKL-code; TALE-code; TBX-code

\section{Introduction}

Stem and progenitor cells pass through several developmental stages and subsequently differentiate into mature cells and tissues. During early embryogenesis, hematopoietic and endothelial cells share a common progenitor, termed hemangioblast. Later in development, these cell types differentiate separately, starting from hematopoietic and endothelial stem cells, respectively. The process of hematopoiesis generates all types of blood and immune cells, split into the lymphoid and myeloid lineages. The latter produces mature cell types such as erythrocytes and megakaryocytes via the joint megakaryocyte and erythroid progenitor [1]. Megakaryocytes develop subsequently the thrombocytes.

Differentiation processes during hematopoietic and endothelial development are mainly regulated at the transcriptional level $[2,3]$. The master genes responsible for controlling these processes mostly encode transcription factors (TFs). E26 transformation-specific (ETS) and NKL homeodomain factors represent two types of such developmental TFs 
and operate at specific stages and lineages. ETS factors share the conserved ETS domain, which forms a winged helix-turn-helix structure and performs both sequence-specific DNA binding and protein-protein interactions [4]. According to sequence similarities, their genes are classified into 13 groups [5]. ETV2 and FLI1 are two basic ETS factors of the ERG group, regulating early steps in hematopoietic and endothelial development. ETV2 is expressed in the hemangioblast and drives endothelial differentiation in the adult, while FLI1 is active both in hematopoietic stem cells (HSCs) and during megakaryopoiesis [6,7]. Homeobox genes encode a homeodomain that consists of three helices, generating a helix-turn-helix structure. The homeodomain performs an interaction with DNA, cofactors, and chromatin, forming a platform for gene regulation [8]. According to sequence similarities of their conserved homeobox, these genes are arranged into eleven classes and several subclasses [9]. Thus, for example, NKL homeobox genes represent a subclass of the Antennapedia (ANTP) class of homeobox genes. The human genome contains 49 NKL homeobox genes that play fundamental roles in embryonal development of tissues and organs and regulate cell differentiation in the adult. Examples are NKX2-3, which is expressed in developing spleen, intestine and in HSCs; NKX2-4, which is active in brain and testis development; and NKX2-5, which controls development of heart and spleen [10-14]. Recently, we have described the NKL-code that encompasses the gene signature of eleven NKL homeobox genes expressed in specific patterns during hematopoiesis [15]. Basic NKL-code members are NKX2-3, in addition to both HHEX and HLX, which orchestrate differentiation processes in myeloid and lymphoid lineages and are themselves regulated by specific hematopoietic TFs [16].

According to their functions in normal development, deregulated ETS and NKL homeobox genes promote generation of hematopoietic malignancies and are frequently targeted by chromosomal aberrations. For example, the ETS gene ETV6 is fused with different partner genes by specific translocations in lymphoblastic and myeloid acute leukemias, and NKL homeobox gene NKX2-5 is aberrantly activated via juxtaposition to an enhancer region of $B C L 11 B$ in T-cell acute lymphoblastic leukemia (T-ALL) $[17,18]$. Other reported activating mechanisms for NKL homeobox genes are deregulated chromatin components, signaling pathways, and TFs [15]. Furthermore, aberrantly expressed ETS and NKL homeobox genes serve as diagnostic markers for certain hematopoietic cancers, such as ETV6 in ALL and TLX1 in T-ALL.

Acute myeloid leukemia (AML) is the most frequent acute leukemia in adults. The tumor cells derive from specific progenitor cells of the myeloid lineage. According to originating cells and stages, phenotypes, chromosomal aberrations, and gene mutations, several subtypes of AML are distinguished that differ in prognosis and treatment. The established French-American-British (FAB) system differentiates eight subtypes, called AML-M0 to -M7 [19]. Thus, for example, AML-M6 represents an erythroblastic subtype and the corresponding tumor cells express several erythropoietic genes and are blocked in development, unable to terminate differentiation. Today, additional criteria including sequencing data basically serve to classify AML [20].

Systematic analysis of NKL homeobox genes in AML has revealed 18 deregulated genes, highlighting the importance of these developmental oncogenes in driving this malignancy [21]. Focused studies in AML have investigated activating factors and downstream functions of the selected deregulated NKL homeobox genes NANOG, HMX2, and HMX3 and have shown the oncogenic roles of these genes [21,22]. In this study, we performed detailed analyses of the oncogenically deregulated NKL homeobox gene NKX2-4 using AML cell line OCI-M2 as model. We found that NKX2-4 is aberrantly connected with the developmental ETS genes ETV2 and FLI1, generating a leukemogenic network, which impacts myeloid differentiation. 


\section{Results}

\subsection{NKX2-4 Expression in AML Cell Line OCI-M2}

Systematic examinations of aberrantly expressed NKL homeobox genes in AML patients and cell lines were performed using public gene expression profiling datasets, highlighting their frequent deregulation and oncogenic impact in this myeloid malignancy [21]. To investigate their pathological function in myeloid in vitro models, we searched for deregulated NKL homeobox genes in our published RNA-seq dataset LL-100, which covers 34 myeloid and 66 lymphoid leukemia/lymphoma cell lines. We detected NKX2-4 expression in two AML cell lines, conspicuously high in OCI-M2 and low in THP-1 (Figure 1A). Additionally, B-cell lymphoma cell line U-2932 expressed elevated NKX2-4 levels as well. Importantly, this NKL homeobox gene is not represented in standard expression profiling arrays, and its transcriptional deregulation has, therefore, yet to be reported in leukemia patients or cell lines.
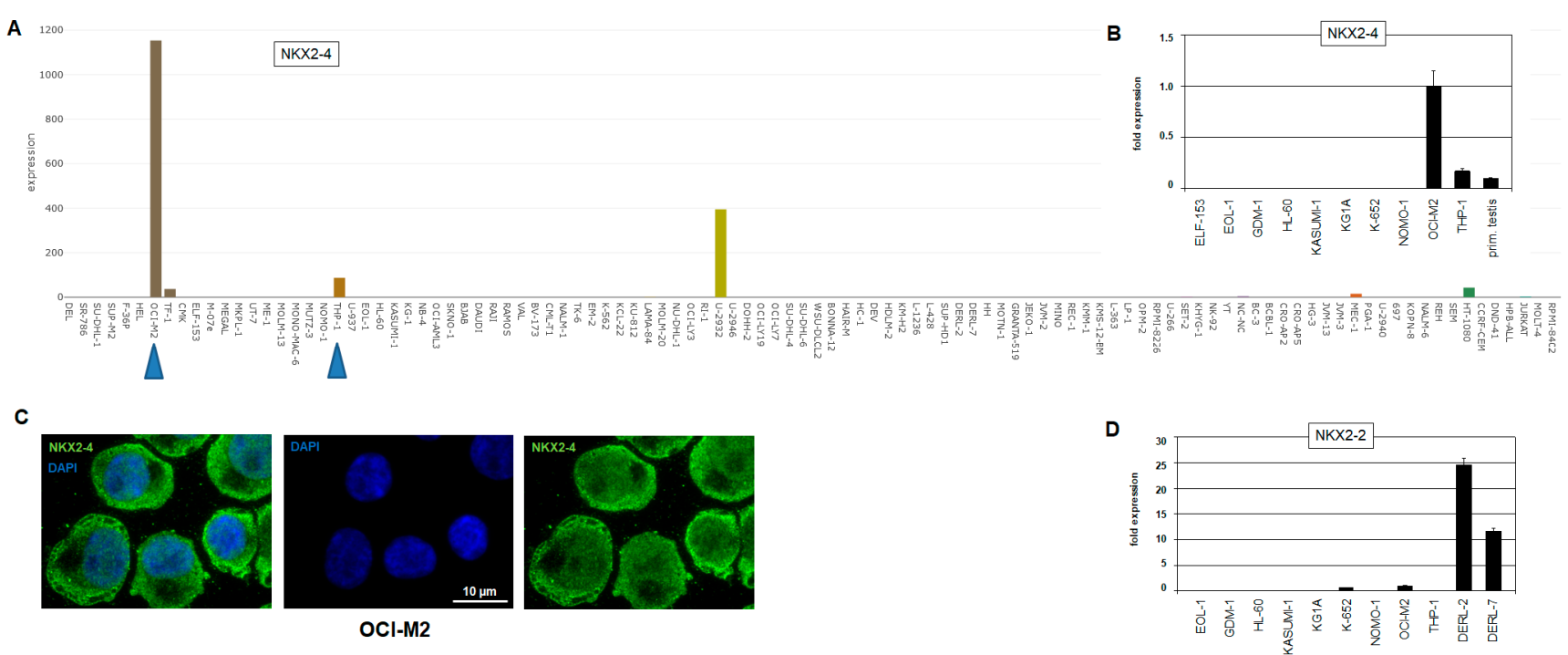

Figure 1. NKX2-4 expression in hematopoietic cell lines. (A) LL-100 RNA-seq data show enhanced expression of NKL homeobox gene NKX2-4 in AML cell line OCI-M2, while THP-1 expresses low levels (blue arrow heads). Gene expression values are given as DESeq2 normalized count data. (B) RQ-PCR analysis confirms high transcript levels in OCI-M2, while THP-1 and primary testis express lower levels. The expression level in OCI-M2 was set as 1. (C) Immunostaining of NKX2-4 protein in OCI-M2 cells, showing signals in both cytoplasm and nucleus (green). DAPI was used as nuclear counterstain (blue). (D) RQ-PCR analysis of NKX2-2 in selected AML cell lines and T-cell lymphoma cell lines DERL-2 and DERL-7 shows elevated transcript levels in the latter, while THP-1 tested negative. The expression level in OCI-M2 was set as 1.

Analyses of additional public RNA-seq datasets containing samples from normal cells and tissues showed an absence of NKX2-4 expression in developing and mature hematopoietic cells but showed its presence in the hypothalamus, pituitary gland, and testis (Figure S1). RQ-PCR and immunostaining confirmed NKX2-4 activity in OCI-M2 cells at the RNA and protein levels, respectively (Figure 1B,C). The subcellular distribution of NKX2-4 protein showed localization in both nucleus and cytoplasm, suggesting functional regulation of this TF via nuclear import. Furthermore, combined analysis of NKX2-4 in a primary testis sample indicated enhanced transcript levels in OCI-M2 (Figure 1B). Thus, NKX2-4 is ectopically overexpressed in AML cell line OCI-M2, which was therefore used as a model to investigate its oncogenic role in this malignancy, including activating mechanisms and target genes.

\subsection{Karyotyping and Genomic Profiling of OCI-M2}

NKL homeobox genes are frequently deregulated by chromosomal aberrations [15]. To check if the NKX2-4 locus is targeted by chromosomal rearrangements, we performed 
karyotyping of OCI-M2. The resultant karyotype was as follows: 51(46-51) $<2 \mathrm{n}>\mathrm{XX}$, $\operatorname{der}(\mathrm{X}) \mathrm{t}(\mathrm{X} ; 8)(\mathrm{q} 23 ; \mathrm{q} 23),+6,+8, \operatorname{add}(9)(\mathrm{p} 23), \operatorname{del}(9)(\mathrm{p} 12 \mathrm{p} 21), \mathrm{t}(10 ; 12)(\mathrm{p} 12 ; \mathrm{p} 12), \operatorname{del}(17)(\mathrm{q} 11 \mathrm{q} 21.1)$, $+20,-21,+3$ mar. However, no aberrations of the NKX2-4 locus at 20p11 were detected in OCI-M2. Nevertheless, the observed trisomy of chromosome 20 may boost NKX2-4 expression by copy number gain.

Furthermore, we performed genomic profiling analysis of OCI-M2 to identify potential copy number alterations. The data for all chromosomes are shown in Figure 2, indicating, however, absence of a focal gain at the NKX2-4 locus. In contrast, the results show several copy number alterations at other chromosomal positions, including duplications at 7q31q36 and 8q22-q24, strongly amplified regions at 19p13 and 21q22, and deletions at 9p23-p24, 12p12, Xp11, and Xq12-q22. These regions may be indirectly implemented in NKX2-4 deregulation. Interestingly, genomic profiling data of THP-1 cells that weakly transcribed NKX2-4 showed a focal amplification at the NKX2-4 locus (Figure S2A). However, this aberration neither enhanced the expression level of NKX2-4 nor of the expression of its gene neighbor NKX2-2, as demonstrated by RQ-PCR analysis (Figure 1B,D), indicating absence of cognate activating TFs in THP-1. Of note, T-cell lymphoma cell lines DERL-2 and DERL-7 have been shown to aberrantly express NKX2-2 and were used here as controls [23].

\subsection{OCI-M2 Displays an Aberrant Program of Endothelial Development}

To identify NKX2-4 activating factors, we performed comparative expression profiling analysis of AML cell line OCI-M2 versus 31 AML control cell lines using public dataset GSE59808 and the associated online tool GEOR, which calculates the 250 most highly statistically significant differences in gene expression levels. This examination revealed for OCI-M2 differentially expressed up- or downregulated genes (Table S1). Subsequent gene set annotation analysis of these genes using the public online platform DAVID showed several significantly associated GO terms, including activated chromatin/histones and endothelial signaling (Table S2). The latter GO term was of special interest because of the close relationships between endothelial and hematopoietic development.

In support of this finding, OCI-M2 overexpressed ETV2, encoding a master factor for endothelial development, in addition to members of its associated gene signature, including EPOR, HEY1, KDR, and SOX7 [24-26] (Table S1). RNA-seq data, RQ-PCR, and Western blot analyses of selected AML cell lines confirmed enhanced expression of these genes in OCI-M2 (Figure 3A-C and Figure S3). Furthermore, according to the comparative expression profiling data, IRF6 and the histone genes H1C and H2BB from the HIST1cluster were also overexpressed, while FLI1 and KDM6A were downregulated in OCI-M2 (Figure 3D,E and Figure S3, Table S1). Of note, IRF6 has been associated with endothelial development as well [27], thus representing an additional overexpressed TF in this context.

Interestingly, overexpressed ETV2 is located at chromosomal position 19p13, which is targeted by genomic amplification in OCI-M2, while suppressed KDM6A is located at Xp11, which is focally deleted (Figure 2 and Figure S2B). Thus, these genomic aberrations may directly cause the deregulated activities observed for the indicated genes. Whole chromosome gains may underlie elevated expression levels of HIST1-genes at 6p22, SOX7 at $8 \mathrm{p} 23$, HEY1 at $8 \mathrm{q} 21$, and NKX2-4 at 20p11 (Figure 2). However, a potential role for overexpressed histone genes in aberrant NKX2-4 expression remained unclear, although we additionally detected elevated levels of ubiquitinated H2B in OCI-M2 (Figure 3D), which has been shown to impact NKL homeobox gene activity in B-cell lymphoma [28]. Taken together, AML cell line OCI-M2 displays an aberrantly activated program for endothelial development, which may drive its oncogenic transformation, notably including NKX24 expression. Copy number alterations may underlie aberrant activation of particular endothelial signature genes. 

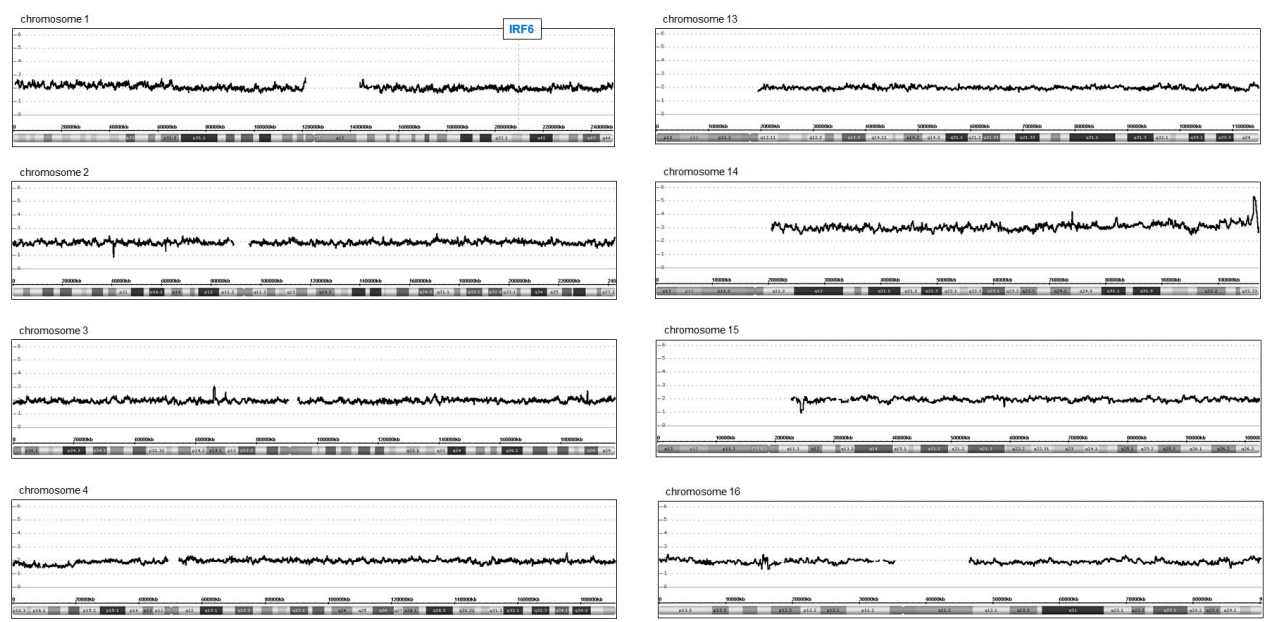

chromosome 5
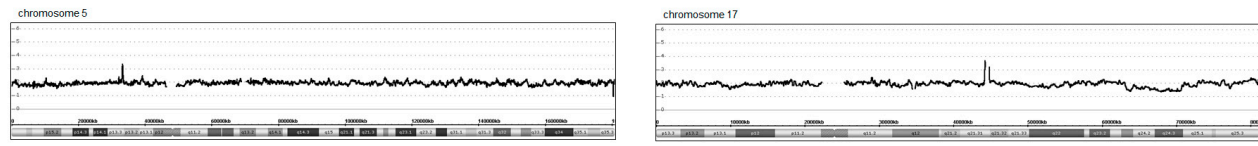

chromosome6 HIST1

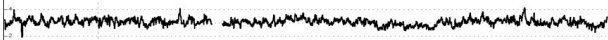

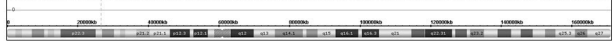
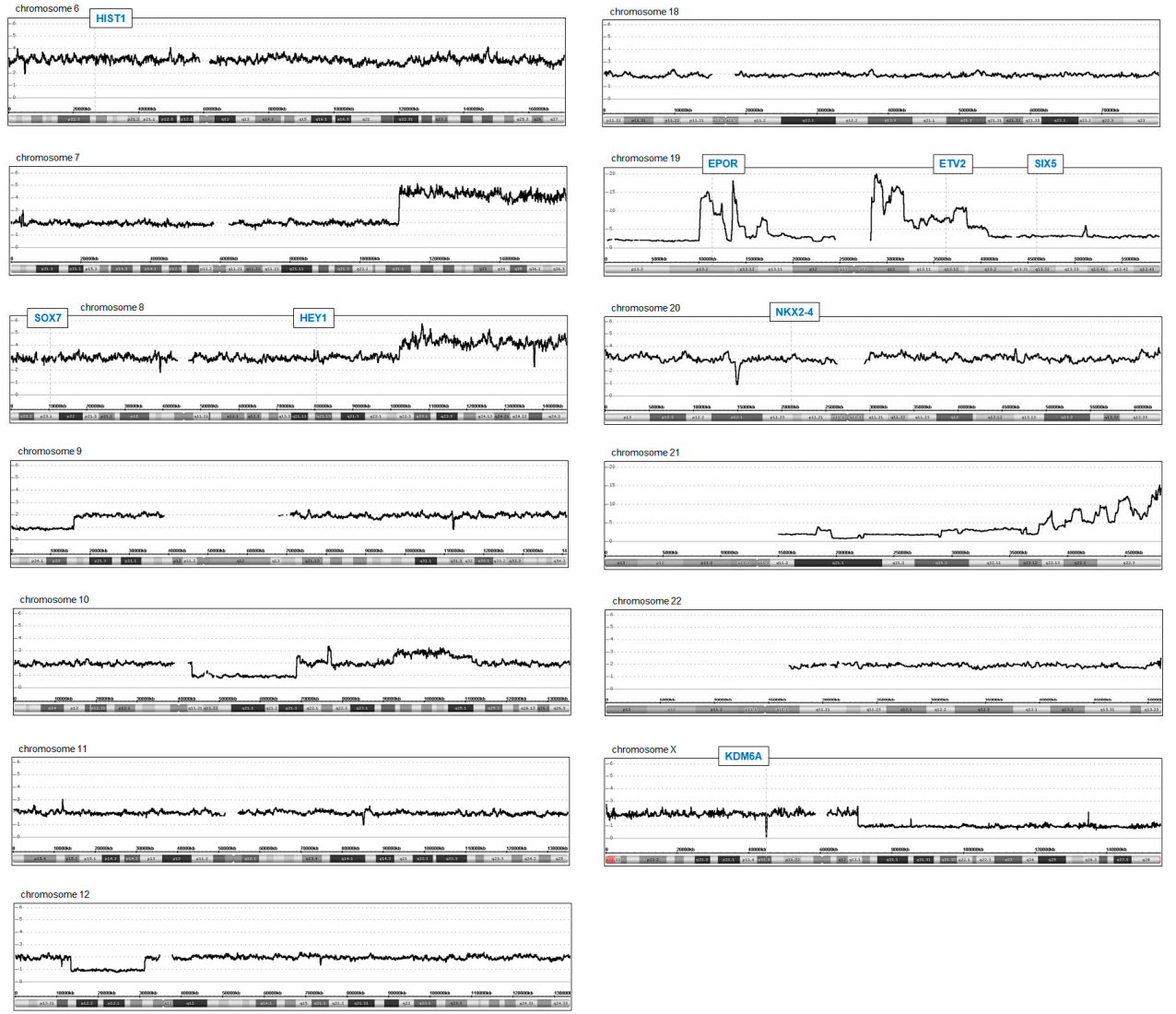

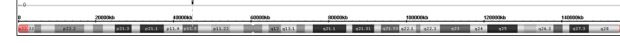

Figure 2. Genomic profiling data of OCI-M2. The data show copy number states for all chromosomes. The $y$-axis indicates the copy number state, the $x$-axis the chromosomal position. Selected gene loci are indicated, including IRF6, HIST1, SOX7, HEY1, EPOR, ETV2, SIX5, NKX2-4, and KDM6A. 

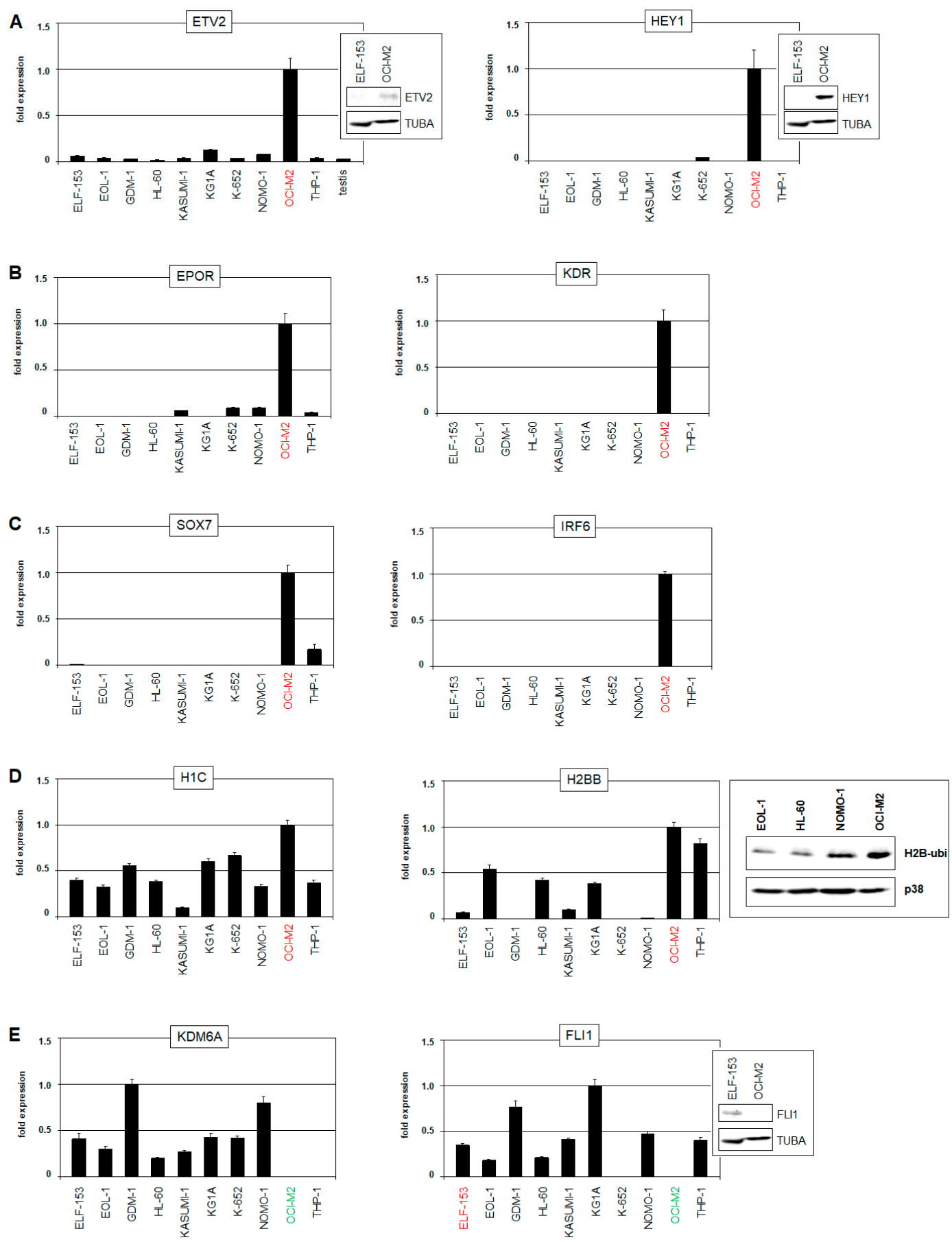

Figure 3. RQ-PCR and Western blot analysis of selected genes in AML cell lines. (A) RQ-PCR and Western blot analyses of ETV2 (left) and HEY1 (right) demonstrate elevated expression levels in OCI-M2. (B) RQ-PCR analyses of EPOR (left) and KDR (right) demonstrate increased expression levels in OCI-M2. (C) RQ-PCR analyses of SOX7 (left) and IRF6 (right) demonstrate elevated expression levels in OCI-M2. (D) RQ-PCR analyses of H1C (left) and H2BB (middle) demonstrate high expression levels in OCI-M2. Raised levels of ubiquinated H2B are shown by Western blot analysis, using p38 as loading control (right). (E) RQ-PCR and Western blot analyses of KDM6A (left) and FLI1 (right) demonstrate reduced expression levels in OCI-M2. The cell lines OCI-M2 and ELF-153 are indicated in red and green. The expression levels of OCI-M2 were set as 1, except for analyses of KDM6A (GDM-1 was set as 1) and FLI1 (KG1A was set as 1).

\subsection{Endothelial Transcription Factors Activate NKX2-4 in OCI-M2}

To examine whether the overexpressed endothelial TFs contribute to NKX2-4 expression, we screened its promoter region for potential TF binding sites, using the UCSC 
genome browser. This approach revealed a SOX consensus site, as shown in Figure 4A. Accordingly, siRNA-mediated knockdown of overexpressed SOX7 in OCI-M2 resulted in concomitantly reduced NKX2-4 expression, showing that this endothelial TF activated NKL homeobox gene NKX2-4 (Figure 4B). Then, a search for additional potential binding sites at NKX2-4 using the CIS-BP database indicated an IRF6-site at $-2648 \mathrm{bp}$, an ETV2-site at $-2021 \mathrm{bp}$, and a HEY1-site within exon 2. To analyze their regulatory impact on NKX2-4 expression, we performed corresponding siRNA-mediated knockdown experiments. The results showed that all three factors-IRF6, ETV2 and HEY1-activated expression of NKX2-4 in OCI-M2 (Figure 4C,D).

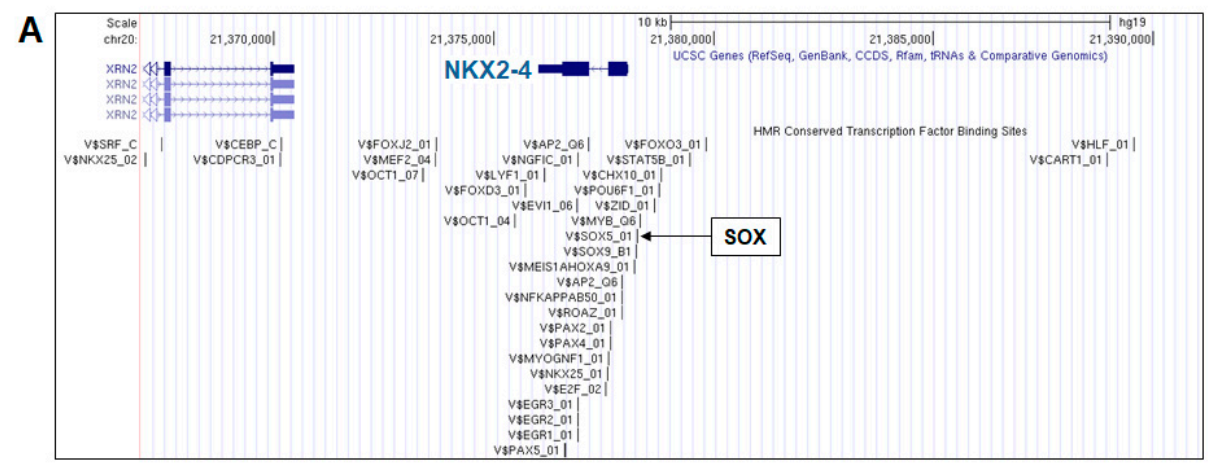

B
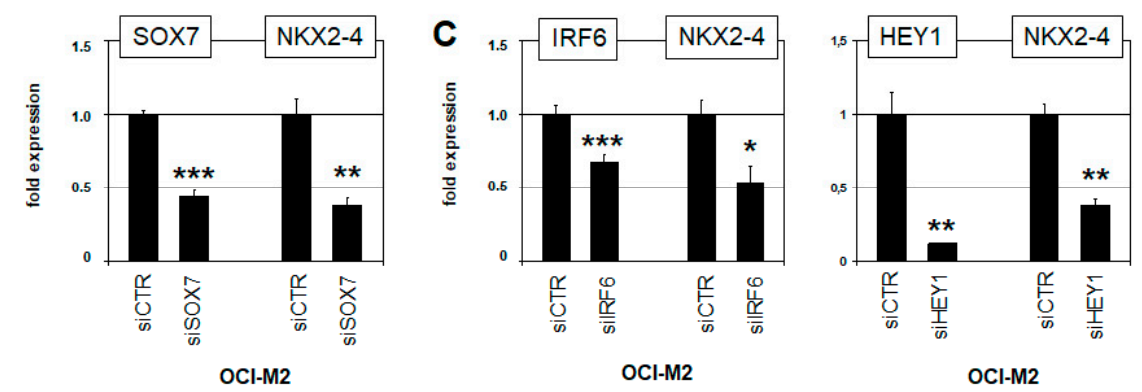

D
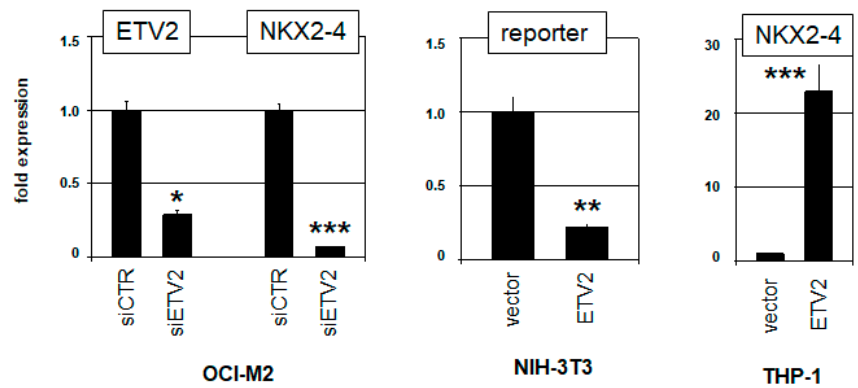

Figure 4. Endothelial TFs activate NKX2-4 in OCI-M2. (A) TF binding sites at the NKX2-4 locus were obtained from the UCSC genome browser. A consensus binding site for SOX factors is indicated. (B) RQ-PCR analysis of OCI-M2 after siRNA-mediated knockdown of SOX7 shows concomitantly reduced transcript levels of NKX2-4. (C) RQ-PCR analyses of OCI-M2 after siRNA-mediated knockdown of IRF6 (left) and HEY1 (right) show concomitantly reduced transcript levels of NKX2-4. (D) RQ-PCR analysis of OCI-M2 after siRNA-mediated knockdown of ETV2 shows concomitantly reduced transcript levels of NKX2-4 (left). Reporter gene assay for a potential ETV2 binding site at NKX2-4 was performed in NIH-3T3 cells, showing a suppressive effect. Nevertheless, these contextdependent results may indicate direct regulation of NKX2-4 by ETV2 (middle). Forced expression of ETV2 in THP-1 cells resulted in strongly elevated NKX2-4 expression (right). Statistical significance was assessed by Student's $t$-test (two-tailed), and the calculated $p$-values are indicated by asterisks $\left({ }^{*} p<0.05,{ }^{* *} p<0.01,{ }^{* * *} p<0.001\right.$, n.s. not significant). The expression levels of siCTR-treated and vector-treated cells were set as 1 . 
To study the role of ETV2 in more detail, we established a reporter gene assay for the identified binding site, showing that ETV2 regulated NKX2-4 directly (Figure 4D). Furthermore, forced expression of ETV2 in THP-1 cells resulted in strongly elevated transcript levels of NKX2-4 (Figure 4D), highlighting the activatory power of this TF in AML cells. Taken together, the endothelial TFs SOX7, IRF6, HEY1, and ETV2 are aberrantly overexpressed activators of NKX2-4 in AML cell line OCI-M2.

\subsection{NKX2-4 Impacts Erythroid Development}

Functional analyses of NKX2-4 were performed by life-cell imaging. Accordingly, OCIM2 cells were treated for NKX2-4 knockdown and subsequently quantified for proliferation and apoptosis (Figure 5A). However, the results show no significant impact on these processes. The better to understand the potential oncogenic role of TF NKX2-4 in AML, we searched for its target genes. We postulated that the above-identified NKX2-4 regulators ETV2 and HEY1 may simultaneously represent NKX2-4 target genes because they contain consensus binding sites for NKX2-4 at $-1235 \mathrm{bp}$ and $-961 \mathrm{bp}$, respectively. Moreover, indeed, siRNA-mediated knockdown of NKX2-4 resulted in concurrent downregulation of ETV2 and HEY1, confirming targeting of these genes by NKX2-4 and thus their participation in an aberrant mutually activating network (Figure 5B). The known role of ETV2 and HEY1 in endothelial development may indicate that NKX2-4 deregulates differentiation processes in AML.

To search for NKX2-4 target genes more systematically, we performed expression profiling analysis of OCI-M2 after NKX2-4 knockdown in comparison with a control (Table S3). Gene set annotation analysis of the top-1000 upregulated and downregulated genes revealed several GO terms associated with tissue and organ development (Table S4). Thus, these results further support that NKX2-4 may deregulate developmental processes in AML. However, this approach showed no GO term specifically associated with myeloid differentiation. Therefore, after inspection of these differentially expressed genes, we selected six myeloid-associated candidates encoding TFs, receptors, and markers for detailed analyses-namely FLI1, FOXA1, MAML2, SIX5, SIRPA, and TGFBR1 [7,29-33]. Again, siRNA-mediated knockdown of NKX2-4 in OCI-M2 and subsequent transcript quantification by RQ-PCR confirmed that NKX2-4 activated FOXA1, MAML2, and SIX5 (Figure 5C) and repressed FLI1 and SIRPA (Figure 5D). The identified NKX2-4 target genes may thus play a role in deregulated myeloid development and thus in the leukemogenesis of OCI-M2.

To evaluate our findings, we analyzed gene expression data obtained from primary samples, including peripheral blood cells from AML patients as well as hematopoietic progenitor cells from healthy donors. OCI-M2 is derived from a patient with acute erythroblastic leukemia, AML-M6 [34]. To compare our cell line data with those from patients, we performed comparative expression profiling analysis of samples from six AML-M6 patients versus 429 controls (patients with AML-M0, -M1, -M2, -M3, -M4, and -M5) using public dataset GSE6891 and analysis tool GEOR. Differentially expressed genes revealed by this approach included significantly upregulated EPOR, GATA1, HIST1, IRF6, and SIX5, and significantly downregulated FLI1 in AML-M6 (Table S5). Thus, key regulators and target genes of NKX2-4 identified in OCI-M2 are likewise expressed in AML-M6 patients, verifying the clinical relevance of our data obtained from a cell line model. 
A

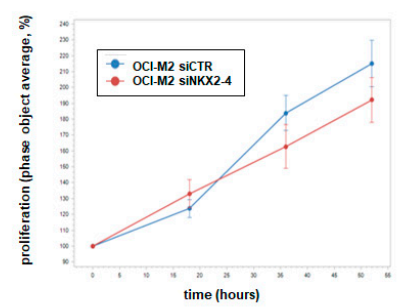

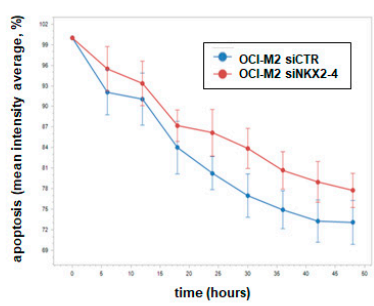
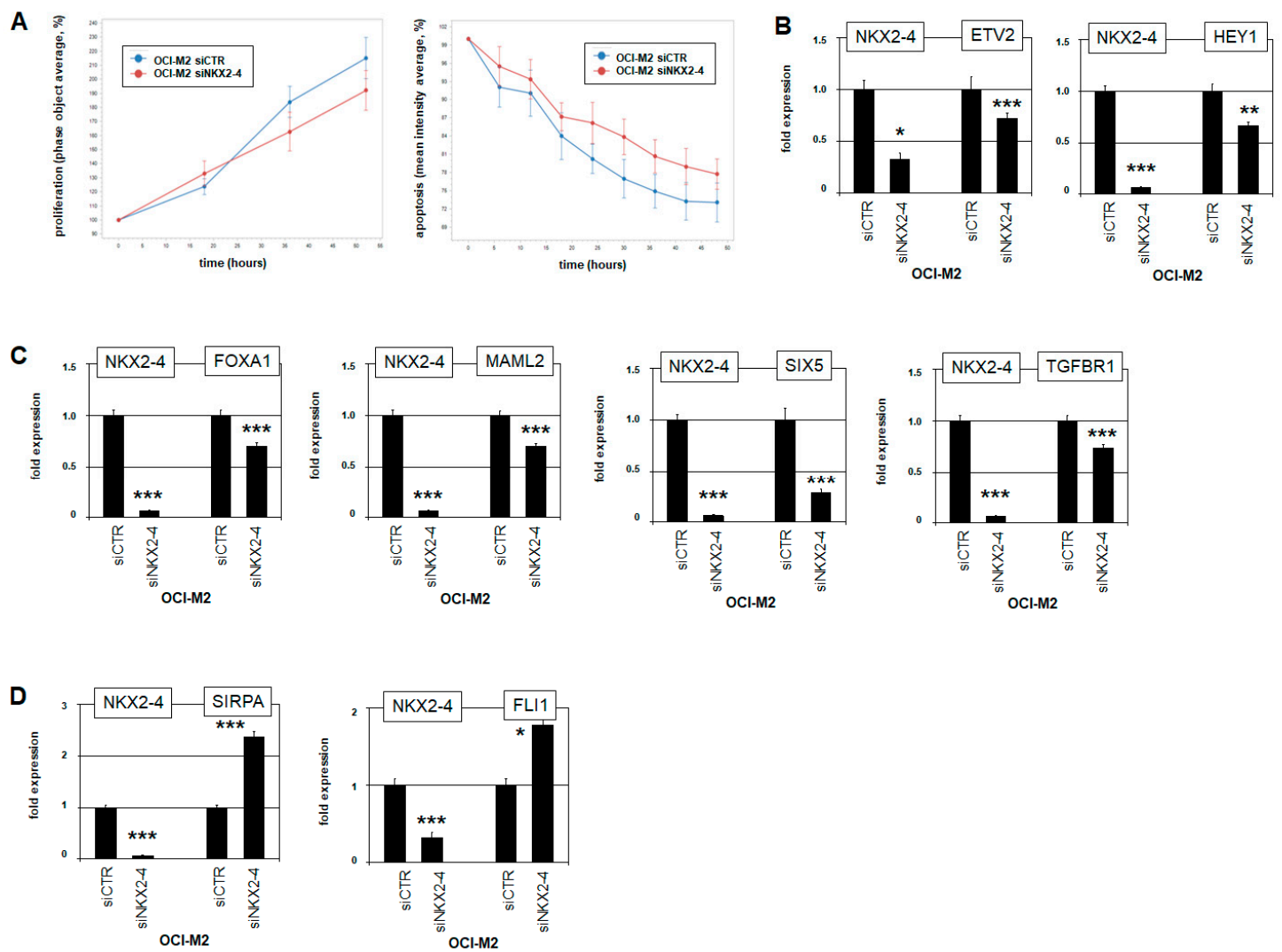

E
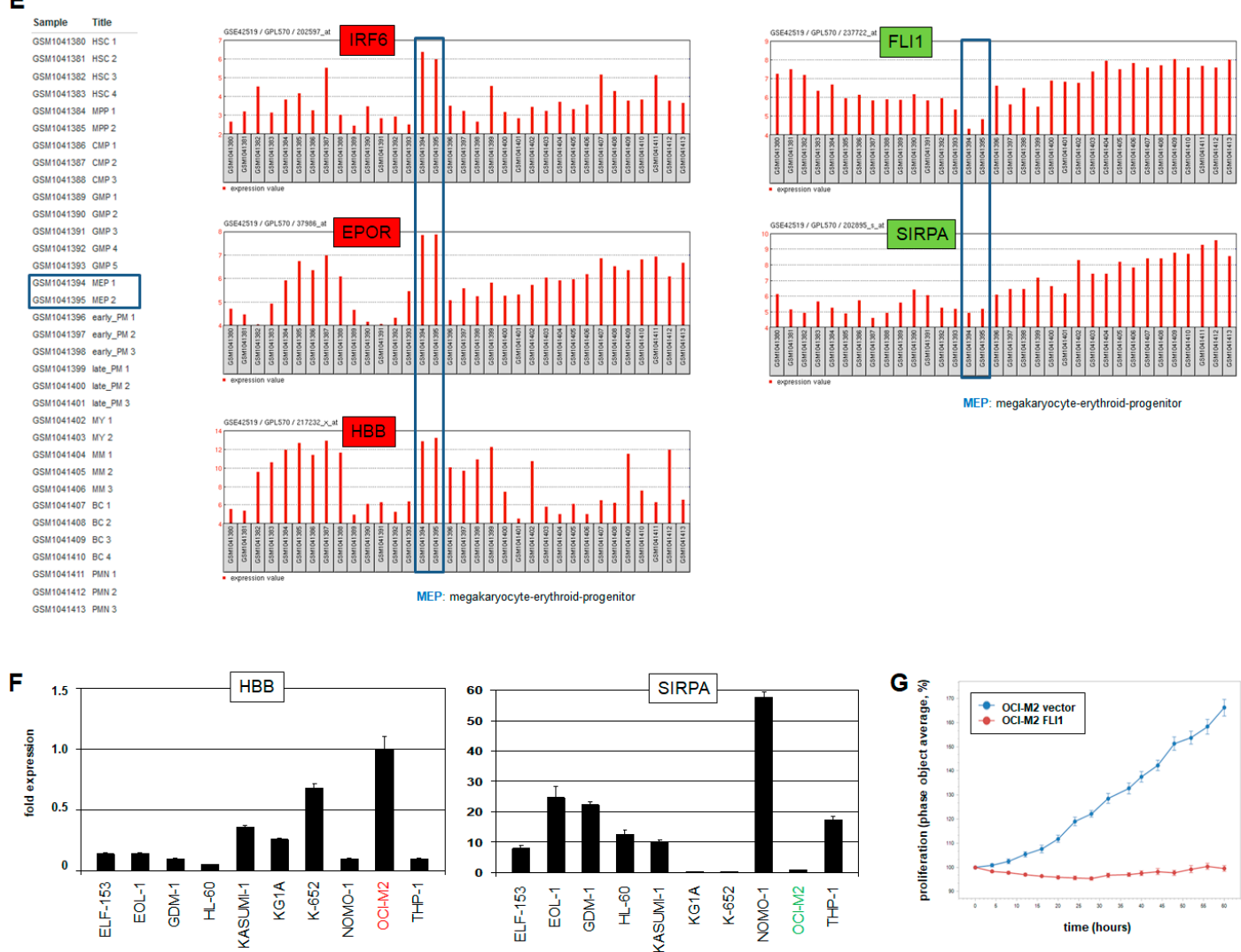

Figure 5. NKX2-4 target gene analyses. (A) Life-cell imaging analysis of OCI-M2 cells treated by siRNA-mediated knockdown of NKX2-4 show no significant impact in proliferation (left) or apoptosis (right). (B) RQ-PCR analyses of 
ETV2 (left) and HEY1 (right) in OCI-M2 after siRNA-mediated knockdown of NKX2-4 confirm these genes as activated targets. (C) RQ-PCR analyses of FOXA1, MAML2, SIX5, and TGFBR1 in OCI-M2 after siRNA-mediated knockdown of NKX2-4 confirm these genes as activated targets. (D) RQ-PCR analyses of SIRPA (left) and FLI1 (right) in OCI-M2 after siRNA-mediated knockdown of NKX2-4 confirm these genes as suppressed targets. (E) Expression profiling analysis of developing myeloid cells using public dataset GSE42519 shows elevated expression levels of IRF6, EPOR, and HBB and reduced levels of FLI1 and SIRPA in megakaryocyte-erythroid progenitor cells (MEP). The y-axis represents the expression levels. (F) RQ-PCR analysis of selected AML cell lines for HBB (left) and SIRPA (right) show respective elevated and reduced expression levels in OCI-M2. (G) Life-cell imaging analysis of OCI-M2 cells treated by forced expression of FLI1 shows significant reduction in proliferation. Statistical significance was assessed by Student's $t$-test (two-tailed), and the calculated $p$-values are indicated by asterisks $\left({ }^{*} p<0.05,{ }^{* *} p<0.01,{ }^{* * *} p<0.001\right.$, n.s. not significant). The expression levels of siCTR-treated cells and of untreated OCI-M2 were set as 1.

In addition, we compared expression profiling data of samples from normal megakaryocyte and erythroid progenitors (MEPs) versus more differentiated granulopoietic progenitors, including promyelocytes, myelocytes, metamyelocytes, and band cells, using dataset GSE42519 and analysis tool GEOR. This approach revealed downregulated FLI1 and SIRPA and upregulated IRF6, EPOR, GATA1, and HBB in MEPs (Table S6, Figure 5E). FLI1, SIRPA, GATA1 and HBB play basic roles in myeloid development especially in erythropoiesis [7,32,35]. Accordingly, RQ-PCR analysis demonstrated that OCI-M2 expressed elevated GATA1 and HBB and reduced SIRPA levels as well (Figure 5F), consistent with its erythroblastic phenotype resembling MEPs.

FLI1 encodes a key myeloid TF, repressing erythroid while activating megakaryocytic differentiation $[7,36]$. Therefore, aberrant suppression of FLI1 by NKX2-4 in OCI-M2 may promote leukemogenic transformation towards erythroblastic cells. Accordingly, forced expression of FLI1 in OCI-M2 cells inhibited proliferation, suggesting that FLI1-mediated cell differentiation processes are uniformly connected with termination of cell growth (Figure 5G). Taken together, our experimental data for NKX2-4 in acute erythroblastic leukemia cell line OCI-M2 correspond to expression data from AML-M6 patients and primary MEPs, suggesting that this aberrantly activated NKL homeobox gene may provoke a developmental defect in the process of megakaryocyte-erythroid differentiation.

\subsection{NKX2-3 Impacts Megakaryocytic Development}

As mentioned above, NKX2-4 is not represented in standard expression profiling datasets. However, our comparative profiling results of AML patients (M6 versus M0 to M5) showed ectopic expression of NKL homeobox gene NKX2-3 in AML-M6 patients (Table S5). This finding indicated that NKX2-3 and the closely related TF NKX2-4 may control similar oncogenic processes in this particular AML subtype. To compare their regulatory impacts in vitro, we searched for an NKX2-3 expressing AML cell line model. Anew screening of RNA-seq dataset LL-100 revealed cell line ELF-153 which, however, derives from acute megakaryoblastic leukemia, AML-M7 [37]. RQ-PCR and Western blot analyses confirmed NKX2-3 expression in ELF-153 at the RNA and protein level, respectively, validating its suitability for functional tests (Figure 6A).

Subsequent siRNA-mediated knockdown experiments in ELF-153 demonstrated that NKX2-3 activated ETV2, SIX5, and FLI1 and suppressed HEY1 (Figure 6B). Thus, NKX2-3 differs from NKX2-4 in regulation of HEY1 and FLI1, while both NKL-TFs activated ETV2 and SIX5. Accordingly, RQ-PCR and Western blot analysis demonstrated that ELF-153 expressed elevated levels of FLI1, and OCI-M2 reduced levels of FLI1 (Figure 3E). Furthermore, siRNA-mediated knockdown of FLI1 in ELF-153 resulted in slightly decreased proliferation, as analyzed by life-cell imaging (Figure 6C). Thus, proliferation was promoted by FLI1 in ELF-153, contrasting with OCI-M2. NKX2-4 is aberrantly expressed in erythroblastic leukemia cell line OCI-M2 and represses FLI1, while NKX2-3 is aberrantly expressed in megakaryoblastic leukemia cell line ELF-153 and activates FLI1. FLI1 contains a consensus binding site for both NKX2-3 and NKX2-4 in its upstream region at $-2564 \mathrm{bp}$, 
suggesting direct regulation. Moreover, both NKX2-3 and FLI1 are physiologically upregulated in HSCs (Figure 6D), indicating aberrant reactivation of their regulatory connection in ELF-153.

A

B

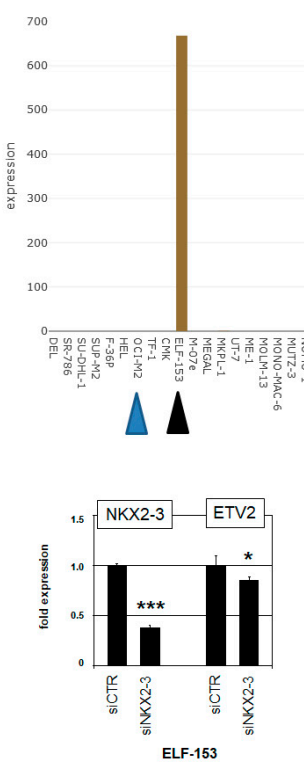

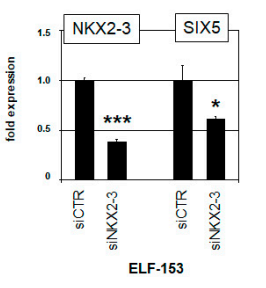

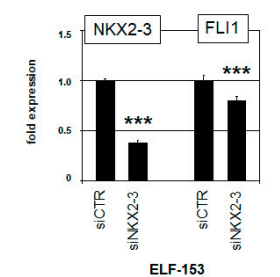

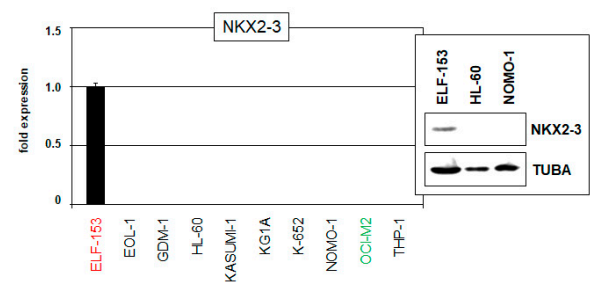

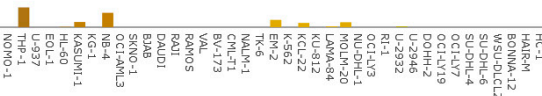
NKX2-3

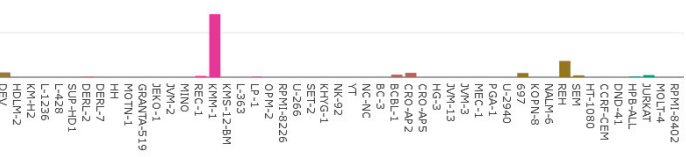

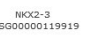

D

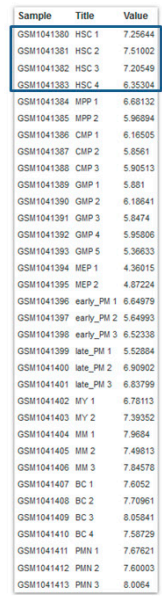

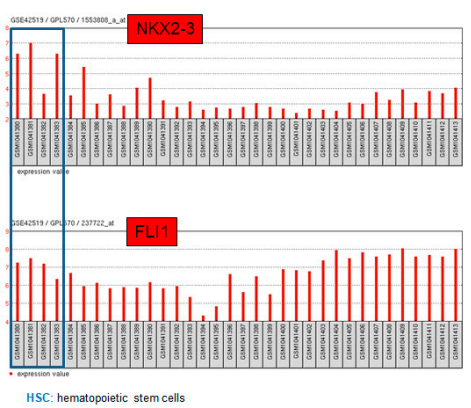

E
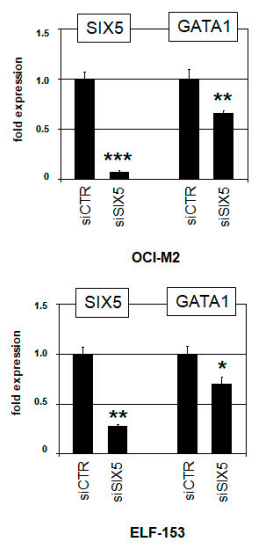

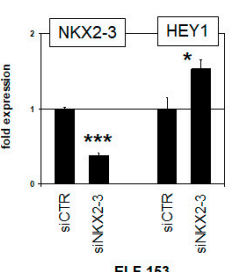

c

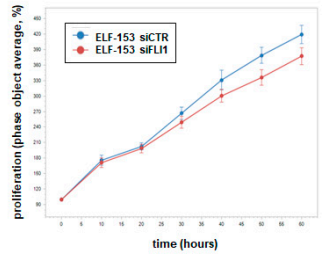

Figure 6. Expression and target gene analysis of NKX2-3. (A) LL-100 RNA-seq data show enhanced expression of NKL homeobox gene NKX2-3 in AML cell line ELF-153 (black arrowhead), while this gene is silent in OCI-M2 (blue arrow heads). Gene expression values are given as DESeq2 normalized count data. RQ-PCR and Western blot analyses of selected AML cell lines confirm enhanced expression of NKX2-3 in ELF-153 (insert). The expression level of ELF-153 was set as 1. (B) RQ-PCR analyses of ETV2 (above left), SIX5 (above right), FLI1 (below left), and of HEY1 (below right) in ELF-153 after siRNA-mediated knockdown of NKX2-3 confirm these genes as targets. Of note, FLI1 is activated by NKX2-3. (C) Life-cell imaging analysis of ELF-153 cells treated for knockdown of FLI1 shows reduction in proliferation $(p=0.021)$. (D) Expression profiling analysis of developing myeloid cells using public dataset GSE42519 shows elevated expression levels of NKX2-3 and FLI1 in hematopoietic stem cells (HSC). (E) RQ-PCR analyses of GATA1, GATA2, and HBB in OCI-M2 (above) and ELF-153 (below) after siRNA-mediated knockdown of SIX5 show differences in gene regulation between these AML cell lines. Statistical significance was assessed by Student's $t$-test (two-tailed), and the calculated $p$-values are indicated by asterisks $\left({ }^{*} p<0.05,{ }^{* *} p<0.01,{ }^{* * *} p<0.001\right.$, n.s. not significant). The expression levels of siCTR-treated cells were set as 1 .

GATA1 and GATA2 represent additional regulators in megakaryopoiesis and erythropoiesis $[35,38]$. Furthermore, GATA1 has been shown to interact with the coactivating TFs 
SIX1 and SIX2 in erythropoiesis, and GATA2 is regulated by SIX1 in embryonal development of the placodes $[39,40]$. Hence, we speculated whether the NKX2-3 and NKX2-4 activated target SIX5 regulates or cooperates with GATA1 and/or GATA2. Thus, we performed SIX5 knockdown experiments in OCI-M2 and ELF-153 (Figure 6E). The results show that SIX 5 activated the expression of GATA1 in both cell lines, while GATA2 was activated by SIX5 only in OCI-M2. GATA1-target gene $H B B$ was suppressed by SIX 5 in ELF-513, while no impact was detectable in OCI-M2. Thus, SIX5 functionally differed in both cell lines. In OCI-M2, SIX5 supported erythropoiesis via GATA1 and GATA2, while in ELF-153, SIX5 supported megakaryopoiesis via GATA1 and inhibited erythropoiesis via $H B B$. Taken together, our findings highlight that the aberrantly expressed NKL homeobox genes NKX2-3 and NKX2-4 manipulate developmental lineage decisions in respective megakaryoblastic and erythroblastic AML via FLI1 deregulation and SIX5 activation.

\section{Discussion}

In this study, we report aberrant expression of NKL homeobox genes NKX2-3 and NKX2-4 in cell lines derived from two different AML subtypes. NKX2-4 is ectopically activated in erythroblastic AML-M6 cell line OCI-M2 via the endothelial TFs ETV2, HEY1, IRF6, and SOX7, generating an aberrant developmental gene network. Prominent target genes identified are repressed FLI1 and activated SIX5 (Figure 7). In contrast, NKX2-3 is aberrantly expressed in megakaryoblastic AML-M7 cell line ELF-153 by so far unknown factors and activates both FLI1 and SIX5 (Figure 7). In AML-M6 patients, we were also able to find gene activities of endothelial activators and target genes of NKX2-4 first identified in OCI-M2. Thus, this comparison with AML patient data revealed interesting concordances, supporting the clinical relevance of our data. Comparison with primary megakaryocyte-erythroid progenitors indicated deregulation of developmental processes by these aberrantly expressed NKL homeobox genes, operating at that developmental stage. Our data revealed deregulation of master factor FLI1. This ETS factor controls the differentiation of megakaryocytes and erythrocytes and may, therefore, represent a new key target in megakaryoblastic and erythroblastic AML.

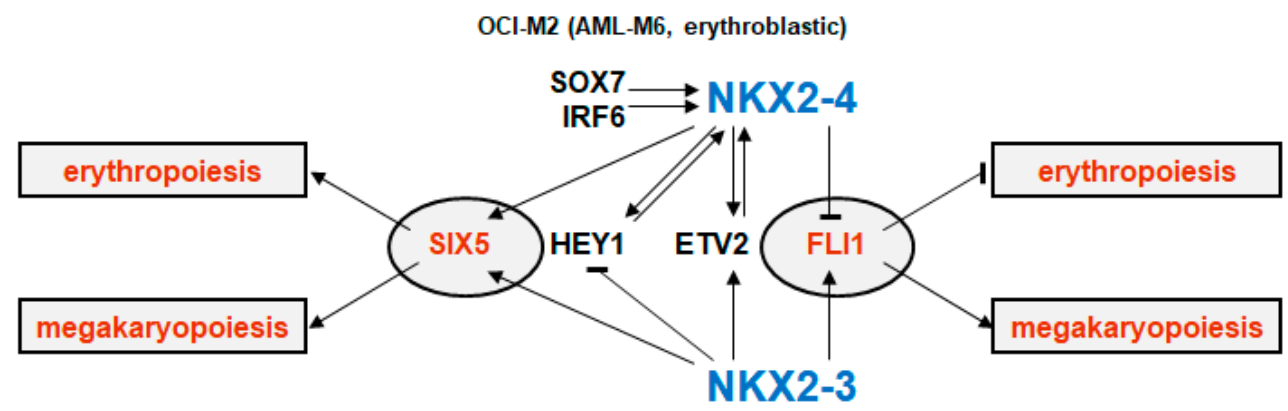

ELF-153 (AML-M7, megakaryoblastic)

Figure 7. Aberrant gene regulatory network of NKX2-4 in OCI-M2 (above) and NKX2-3 in ELF-153 (below). These NKL homeobox genes promote respective erythroblastic and megakaryoblastic leukemogenesis via their target genes FLI1 and SIX5. Endothelial activators of NKX2-4 are indicated.

NKX2-3 is a member of the NKL-code and hematopoietically expressed in HSCs [11]. This restricted expression pattern may indicate a physiological role of this NKL homeobox gene in the control of stemness and lineage differentiation, while its deregulation may promote leukemogenesis by disturbing these developmental processes. Aberrant NKX2-3 activity has been described in AML patients carrying mutations of NPM1 or aberrations of KMT2A [41-43]. Enhanced NKX2-3 expression correlates with KMT2A-rearrangements in T-ALL as well [44]. Moreover, NKX2-3 is a direct target gene of KMT2A-ENL and impacts proliferation and cell differentiation [45]. In accordance with these published results, combined analysis of expression profiling data from normal hematopoietic cells and AML 
patient samples demonstrated physiological NKX2-3 activity in stem cells and aberrant expression in patients with KMT2A rearrangements and complex karyotypes (Figure S4). In addition, NKX2-3 expression has been detected in myelodysplastic syndrome, diffuse large B-cell lymphoma, T-ALL, and T-cell lymphoma, showing its oncogenic potential in both myeloid and lymphoid cell lineages [15]. Increased colony forming and replating capacity after NKX2-3 overexpression has been shown in murine hematopoietic progenitor cells [42], supporting an impact in early differentiation processes.

In contrast, NKX2-4 lies without the NKL-code and is, therefore, normally silent throughout hematopoiesis. This gene is not represented on standard expression arrays and thus is less studied in cancer patients. Nevertheless, a screen of T-ALL patients revealed a chromosomal translocation that juxtaposes NKX2-4 to the TCRA gene, supporting its oncogenic activity in hematopoietic malignancies [46].

Our results show that aberrantly expressed endothelial TFs ETV2, HEY1, IRF6, and SOX7 activate NKX2-4 in AML cell line OCI-M2. The development of endothelial and hematopoietic cell types is closely linked during embryogenesis. The hemangioblast represents an embryonic stem cell that forms the basis of developing blood and endothelial cells. Although this stem cell is absent in the adult, several control genes are shared between these lineages [2]. ETV2 is a master gene of the hemangioblast and regulates endothelial development in the adult [6]. In the embryo, ETV2 activates myelopoiesis via RUNX1, SPI1, and TAL1 [47,48]. In the endothelial development of the heart, ETV2 is a target gene of the heart master factor NKX2-5 [49]. This physiological connection may be aberrantly captured by the related NKX2-4 in OCI-M2. Additional endothelial factors are encoded by FLI1, HEY1, IRF6, and SOX7 [25,27,50,51]. Chromosomal amplifications and chromosomal gains underlie their aberrant activation in OCI-M2. Several of these chromosomal regions are rearranged in erythroleukemic AML patients, including 6p22, 19p13, 20p11, and Xp11, supporting the pathogenic basis of our findings [52].

FLI1 is a master gene in myelopoiesis, driving megakaryocyte differentiation and repressing erythropoiesis [53]. Furthermore, FLI1 is prominently expressed in HSCs, alongside NKX2-3 $[7,11]$. This coexpression, together with our data showing a regulatory connection between both genes, may indicate that FLI1 represents a target gene of NKX2-3 in HSCs as well. B-cell lymphoma cell line U-2932 expressed elevated NKX2-4 and reduced FLI1 (Figure 1 and Figure S3), suggesting that the repressive impact of NKX2-4 may play a role in malignant lymphoid cells as well. FLI1 and IRF6 play a role in both endothelial and erythroid development $[53,54]$. Additional genes connected with NKL homeobox genes in our study are $H B B$ and SIRPA. HBB encodes beta-globin expressed in erythroid progenitors and SIRPA a receptor implicated in innate immunological processes [32]. SIRPA is highly expressed in granulocytes and monocytes, while downregulated in megakaryocytes and erythrocytes [55]. Thus, NKX2-4-mediated inhibition of SIRPA may shift the myeloid differentiation of granulocytes and monocytes towards megakaryocytes and erythrocytes.

SIX1 is implicated in erythropoiesis by interaction with and activation of GATA1 [39]. GATA2 is suppressed by SIX1 and SIX2 during erythropoiesis but activated by SIX1 in Hodgkin lymphoma [39,56]. Furthermore, SIX1 may promote the development of MEPs [57]. Thus, several studies show a regulatory connection between SIX and GATA factors. Here, our data indicate that aberrantly activated SIX5 impacts GATA1 and GATA2 in AML. Depending on the cell type, SIX5 can promote erythropoietic or megakaryopoietic processes.

Taken together, this study shows that FLI1 and SIX5 represent two target genes of NKX2-3 and NKX2-4 that disturb the differentiation of megakaryocytes and erythrocytes. Overexpression experiments of NKX2-3 and NKX2-4 in primary progenitor cells may support this interpretation in the future. However, a developmental impact at the same stage of differentiation was described for NKL homeobox gene DLX4 [58], highlighting the potential of these genes in lineage decisions. Moreover, we also show that deregulated NKX2-3 and NKX2-4 impact developmental gene activities in AML in a context dependent 
manner. Detection of their aberrant expression may assist the diagnosis and prognosis of certain AML subtypes.

\section{Materials and Methods}

\subsection{Bioinformatic Analyses of RNA-Seq and Expression Profiling Data}

For screening cell lines, we exploited RNA-sequencing data from 100 leukemia/ lymphoma cell lines (termed LL-100), available at ArrayExpress (www.ebi.ac.uk/arrayexpress) (accessed on 18 October 2021) via E-MTAB-7721. Gene expression values are given as DESeq2 normalized count data [59]. Expression data for normal cell types were obtained from Gene Expression Omnibus (GEO, www.ncbi.nlm.nih.gov) (accessed on 18 October 2021), using RNA-seq dataset GSE69239 and expression profiling dataset GSE42519 [60,61], in addition to RNA-seq data from The Human Protein Atlas (www.proteinatlas.org) (accessed on 18 October 2021). Gene expression profiling data from AML cell lines and patients were examined using datasets GSE59808 and GSE15434, respectively [62]. Combined expression analysis of normal hematopoietic cells (GSE42519) and AML patients (GSE13159) was performed using the online database BloodSpot [63]. Gene set annotation analysis was performed using the online tool DAVID (www.david.abcc.ncifcrf.gov) (accessed on 18 October 2021) [64]. Consensus binding sites for TFs were obtained from the CIS-BP database (www.cisbp.ccbr.utoronto.ca) (accessed on 18 October 2021) and were used for screening at the UCSC genome browser (www.genome.cse.ucsc.edu) (accessed on 18 October 2021). Expression profiling data from siRNA-treated OCI-M2 cells were generated at the Genome Analytics Facility (Helmholtz Centre for Infection Research, Braunschweig, Germany) using HG U133 Plus 2.0 gene chips (Affymetrix, High Wycombe, UK). The data are available from ArrayExpress via E-MTAB-10941. After RMA background correction and quantile normalization of the spot intensities, the profiling data were expressed as ratios of sample means and subsequently log2 transformed. Data processing was performed via $\mathrm{R} /$ Bioconductor using public limma and affy packages.

\subsection{Cell Lines and Treatments}

Cell lines are held by the DSMZ (Braunschweig, Germany) and cultivated as described previously [65]. All cell lines had been authenticated and tested negative for mycoplasma infection. Modification of gene expression levels was performed using gene-specific siRNA oligonucleotides with reference to AllStars negative Control siRNA (siCTR) obtained from Qiagen (Hilden, Germany). The gene expression constructs for ETV2, NKX2-4, and FLI1, in addition to an empty control-vector, were obtained from Origene (Wiesbaden, Germany). SiRNAs ( $80 \mathrm{pmol})$ and vector DNA $(2 \mu \mathrm{g})$ were transfected into $1 \times 10^{6}$ cells by electroporation using the EPI-2500 impulse generator (Fischer, Heidelberg, Germany) at $350 \mathrm{~V}$ for $10 \mathrm{~ms}$. Electroporated cells were harvested after $20 \mathrm{~h}$ cultivation.

Proliferation and apoptosis were analyzed using the IncuCyte S3 Live-Cell Analysis System (Essen Bioscience, Hertfordshire, UK). For detection of apoptotic cells, we used the IncuCyte Caspase-3/7 Green Apoptosis Assay diluted at 1:2000 (Essen Bioscience, Essen, Germany). Live-cell imaging experiments were performed twice with fourfold parallel tests.

\subsection{Polymerase Chain-Reaction (PCR) Analyses}

Total RNA was extracted from cultivated cell lines using TRIzol reagent (Invitrogen, Darmstadt, Germany). Primary human total RNA derived from testis was purchased from Biochain/BioCat (Heidelberg, Germany). cDNA was synthesized using $5 \mu \mathrm{g}$ RNA, random priming, and Superscript II (Invitrogen). Real time quantitative (RQ)-PCR analysis was performed using the 7500 Real-time System and commercial buffer and primer sets (Applied Biosystems/Life Technologies, Darmstadt, Germany). For normalization of expression levels, we quantified the transcripts of TATA box binding protein (TBP). Quantitative analyses were performed as biological replicates and measured in triplicate. Standard deviations are presented in the figures as error bars. Statistical significance was assessed by 
Student's $t$-test (two-tailed) and the calculated $p$-values are indicated by asterisks $\left({ }^{*} p<0.05\right.$, ${ }^{* *} p<0.01,{ }^{* * *} p<0.001$, n.s. not significant).

\subsection{Protein Analysis}

Western blots were generated by the semi-dry method. Protein lysates from cell lines were prepared using SIGMAFast protease inhibitor cocktail (Sigma, Taufkirchen, Germany). Proteins were transferred onto nitrocellulose membranes (Bio-Rad, Munich, Germany) and blocked with 5\% dry milk powder dissolved in phosphate-buffered saline buffer (PBS). The following antibodies were used: alpha-Tubulin (Sigma, \#T6199), NKX2-4 (Novus Biologicals, Centennial, CO, USA, \#NBP1-91541), ETV2 (MyBioSource, San Diego, CA, USA, \#MBS7112932), HEY1 (Novus Biologicals, \#NBP2-56068), ubiquinated H2B (Cell Signaling, Frankfurt, Germany, \#5546), p38 (Cell Signaling, \#8690), FLI1 (Thermo Fisher Scientific, Darmstadt, Germany, \#MA1-196), NKX2-3 (Abcam, Cambridge, UK, \#ab66366). For loading, control blots were reversibly stained with Poinceau (Sigma) and detection of alpha-Tubulin (TUBA) performed thereafter. Secondary antibodies were linked to peroxidase for detection by Western-Lightning-ECL (Perkin Elmer, Waltham, MA, USA). Documentation was performed using the digital system ChemoStar Imager (INTAS, Göttingen, Germany).

Immuno-cytology was performed as follows: cells were spun onto slides and subsequently air-dried and fixed with methanol/acetic acid for $90 \mathrm{~s}$. Antibodies were diluted 1:20 in PBS containing 5\% BSA and incubated for $30 \mathrm{~min}$. Washing was performed 3 times with PBS. Preparations were incubated with secondary antibody (diluted 1:100) for $20 \mathrm{~min}$. After final washing, cells were mounted for nuclear in Vectashield (Vector Laboratories, Burlingame, CA, USA), containing DAPI. Documentation of subcellular protein localization was performed using an Axio-Imager microscope (Zeiss, Göttingen, Germany) configured to a dual Spectral Imaging system (Applied Spectral Imaging, Neckarhausen, Germany).

\subsection{Karyotyping and Genomic Profiling Analysis}

Karyotyping was performed as described previously [66]. For genomic profiling, genomic DNA of AML cell lines was prepared by the Qiagen Gentra Puregene Kit (Qiagen). Labelling, hybridization, and scanning of Cytoscan HD arrays was performed by the Genome Analytics Facility located at the Helmholtz Centre for Infection Research (Braunschweig, Germany), according to the manufacturer's protocols (Affymetrix, High Wycombe, UK). These arrays base on single nucleotide polymorphisms (SNPs) and allow the determination of copy number states of most gene loci. Data were interpreted using the Chromosome Analysis Suite software version 3.1.0.15 (Affymetrix, High Wycombe, UK) and copy number alterations were determined accordingly.

\subsection{Reporter-Gene Assay}

For creation of reporter gene constructs, we combined a reporter with a regulatory genomic fragment derived from the upstream region of NKX2-4. PCR products of the corresponding genomic region (regulator) and of the HOXA9 gene, comprising exon1-intron1exon2 (reporter), were cloned into respective HindIII/BamHI and EcoRI sites of expression vector pcDNA3 downstream of the CMV enhancer. Oligonucleotides used for the amplification of the regulator were obtained from Eurofins MWG, Ebersberg, Germany. Their sequences were as follows: NKX2-4-for 5'-GATGAAGCTTATAGCCTGAAAACAGAG-3', NKX2-4-rev 5'-AACACTTGCTGGGATCCTTCTG-3'. Introduced restriction sites used for cloning are underlined. Constructs were validated by sequence analysis (Eurofins MWG). Transfections of plasmid-DNA into NIH-3T3 cells were performed using SuperFect Transfection Reagent (Qiagen). Commercial HOXA9 and TBP assays were used for RQ-PCR to quantify the spliced reporter-transcript, corresponding to the regulator activity (Thermo Fisher Scientific). 
Supplementary Materials: The following are available online at https://www.mdpi.com/article/10 .3390/ijms222111434/s1.

Author Contributions: Conceptualization, S.N.; formal analysis, S.N., C.P., C.M. and R.A.F.M.; investigation, S.N.; writing-original draft preparation, S.N.; writing—review and editing, R.A.F.M. All authors have read and agreed to the published version of the manuscript.

Funding: This research received no external funding.

Institutional Review Board Statement: Not applicable.

Informed Consent Statement: Not applicable.

Data Availability Statement: Data is contained within the article or Supplementary Materials. The data presented in this study are available in [Table S3].

Acknowledgments: We thank Hans G. Drexler for critically reading the manuscript.

Conflicts of Interest: The authors declare no conflict of interest.

\section{References}

1. Xavier-Ferrucio, J.; Krause, D.S. Concise review: Bipotent megakaryocytic-erythroid progenitors: Concepts and controversies. Stem Cells 2018, 36, 1138-1145. [CrossRef]

2. Canu, G.; Ruhrberg, C. First blood: The endothelial origins of hematopoietic progenitors. Angiogenesis 2021, $24,199-211$. [CrossRef] [PubMed]

3. Wilson, N.K.; Foster, S.D.; Wang, X.; Knezevic, K.; Schütte, J.; Kaimakis, P.; Chilarska, P.M.; Kinston, S.; Ouwehand, W.H.; Dzierzak, E.; et al. Combinatorial transcriptional control in blood stem/progenitor cells: Genome-wide analysis of ten major transcriptional regulators. Cell Stem Cell 2010, 7, 532-544. [CrossRef]

4. Gallant, S.; Gilkeson, G. ETS transcription factors and regulation of immunity. Arch. Immunol. Ther. Exp. 2006, 54, 149-163. [CrossRef]

5. Laudet, V.; Hänni, C.; Stéhelin, D.; Duterque-Coquillaud, M. Molecular phylogeny of the ETS gene family. Oncogene 1999, 18, 1351-1359. [CrossRef] [PubMed]

6. Wareing, S.; Eliades, A.; Lacaud, G.; Kouskoff, V. ETV2 expression marks blood and endothelium precursors, including hemogenic endothelium, at the onset of blood development. Dev. Dyn. 2012, 241, 1454-1464. [CrossRef] [PubMed]

7. Kruse, E.A.; Loughran, S.J.; Baldwin, T.M.; Josefsson, E.C.; Ellis, S.; Watson, D.K.; Nurden, P.; Metcalf, D.; Hilton, D.J.; Alexander, W.S.; et al. Dual requirement for the ETS transcription factors Fli-1 and Erg in hematopoietic stem cells and the megakar-yocyte lineage. Proc. Natl. Acad. Sci. USA 2009, 106, 13814-13819. [CrossRef]

8. Bürglin, T.R.; Affolter, M. Homeodomain proteins: An update. Chromosoma 2016, 125, 497-521. [CrossRef] [PubMed]

9. Holland, P.W.H.; Booth, H.A.F.; Bruford, E. Classification and nomenclature of all human homeobox genes. BMC Biol. $2007,5,47$. [CrossRef]

10. Pabst, O.; Zweigerdt, R.; Arnold, H. Targeted disruption of the homeobox transcription factor Nkx2-3 in mice results in postnatal lethality and abnormal development of small intestine and spleen. Development 1999, 126, 2215-2225. [CrossRef]

11. Nagel, S.; Pommerenke, C.; Scherr, M.; Meyer, C.; Kaufmann, M.; Battmer, K.; MacLeod, R.A.F.; Drexler, H.G. NKL homeobox gene activities in hematopoietic stem cells, T-cell development and T-cell leukemia. PLoS ONE 2017, 12, e0171164. [CrossRef]

12. Small, E.M.; Vokes, S.; Garriock, R.J.; Li, D.; Krieg, A.P. Developmental expression of the Xenopus Nkx2-1 and Nkx2-4 genes. Mech. Dev. 2000, 96, 259-262. [CrossRef]

13. Lints, T.; Parsons, L.; Hartley, L.; Lyons, I.; Harvey, R. Nkx-2.5: A novel murine homeobox gene expressed in early heart progenitor cells and their myogenic descendants. Development 1993, 119, 419-431. [CrossRef]

14. Brendolan, A.; Ferretti, E.; Salsi, V.; Moses, K.; Quaggin, S.; Blasi, F.; Cleary, M.L.; Selleri, L. A Pbx1-dependent genetic and transcriptional network regulates spleen ontogeny. Development 2005, 132, 3113-3126. [CrossRef]

15. Nagel, S. NKL-Code in Normal and Aberrant Hematopoiesis. Cancers 2021, 13, 1961. [CrossRef] [PubMed]

16. Migueles, R.P.; Shaw, L.; Rodrigues, N.P.; May, G.; Henseleit, K.; Anderson, K.G.; Goker, H.; Jones, C.M.; De Bruijn, M.F.; Brickman, J.M.; et al. Transcriptional regulation of Hhex in hematopoiesis and hematopoietic stem cell ontogeny. Dev. Biol. 2017, 424, 236-245. [CrossRef]

17. Rasighaemi, P.; Ward, A.C. ETV6 and ETV7: Siblings in hematopoiesis and its disruption in disease. Crit. Rev. Oncol./Hematol. 2017, 116, 106-115. [CrossRef] [PubMed]

18. Nagel, S.; Scherr, M.; Kel, A.; Hornischer, K.; Crawford, G.E.; Kaufmann, M.; Meyer, C.; Drexler, H.G.; MacLeod, R.A. Activation of TLX3 and NKX2-5 in t(5;14)(q35;q32) T-cell acute lymphoblastic leukemia by remote $3^{\prime}$-BCL11B enhancers and coregu-lation by PU.1 and HMGA1. Cancer Res. 2007, 67, 1461-1471. [CrossRef] [PubMed]

19. Arber, D.A. Realistic Pathologic Classification of Acute Myeloid Leukemias. Am. J. Clin. Pathol. 2001, 115, 552-560. [CrossRef] [PubMed] 
20. Arber, D.A.; Orazi, A.; Hasserjian, R.; Thiele, J.; Borowitz, M.J.; Le Beau, M.M.; Bloomfield, C.D.; Cazzola, M.; Vardiman, J.W. The 2016 revision to the World Health Organization classification of myeloid neoplasms and acute leukemia. Blood 2016, 127, 2391-2405. [CrossRef]

21. Nagel, S.; Scherr, M.; MacLeod, R.A.F.; Pommerenke, C.; Koeppel, M.; Meyer, C.; Kaufmann, M.; Dallmann, I.; Drexler, H.G. NKL homeobox gene activities in normal and malignant myeloid cells. PLoS ONE 2019, 14, e226212. [CrossRef]

22. Nagel, S.; Pommerenke, C.; Meyer, C.; MacLeod, R.A.F.; Drexler, H.G. Aberrant expression of NKL homeobox genes HMX2 and HMX3 interferes with cell differentiation in acute myeloid leukemia. PLoS ONE 2020, 15, e0240120. [CrossRef]

23. Nagel, S.; Pommerenke, C.; MacLeod, R.A.; Meyer, C.; Kaufmann, M.; Fähnrich, S.; Drexler, H.G. Deregulated expression of NKL homeobox genes in T-cell lymphomas. Oncotarget 2019, 10, 3227-3247. [CrossRef] [PubMed]

24. Sumanas, S.; Choi, K. ETS transcription factor ETV2/ER71/Etsrp in hematopoietic and vascular development. Curr. Top. Dev. Biol. 2016, 118, 77-111. [PubMed]

25. Kanki, Y.; Nakaki, R.; Shimamura, T.; Matsunaga, T.; Yamamizu, K.; Katayama, S.; Suehiro, J.-I.; Osawa, T.; Aburatani, H.; Kodama, T.; et al. Dynamically and epigenetically coordinated GATA/ETS/SOX transcription factor expression is indispensable for endothelial cell differentiation. Nucleic Acids Res. 2017, 45, 4344-4358. [CrossRef]

26. Liu, F.; Li, D.; Yu, Y.Y.; Kang, I.; Cha, M.J.; Kim, J.Y.; Park, C.; Watson, D.K.; Wang, T.; Choi, K. Induction of hematopoietic and en-dothelial cell program orchestrated by ETS transcription factor ER71/ETV2. EMBO Rep. 2015, 16, 654-669. [CrossRef]

27. Cheng, C.-C.; Chang, S.-J.; Chueh, Y.-N.; Huang, T.-S.; Huang, P.-H.; Cheng, S.-M.; Tsai, T.-N.; Chen, J.-W.; Wang, H.-W. Distinct angiogenesis roles and surface markers of early and late endothelial progenitor cells revealed by functional group analyses. $B M C$ Genom. 2013, 14, 1-10. [CrossRef]

28. Nagel, S.; Ehrentraut, S.; Tomasch, J.; Quentmeier, H.; Meyer, C.; Kaufmann, M.; Drexler, H.G.; MacLeod, R.A. Ectopic expression of homeobox gene NKX2-1 in diffuse large B-cell lymphoma is mediated by aberrant chromatin modifications. PLoS ONE. 2013, 8, e61447. [CrossRef]

29. Neben, K.; Schnittger, S.; Brors, B.; Tews, B.; Kokocinski, F.; Haferlach, T.; Muller, J.; Hahn, M.; Hiddemann, W.; Eils, R.; et al. Distinct gene expression patterns associated with FLT3- and NRAS-activating mutations in acute myeloid leukemia with normal karyotype. Oncogene 2005, 24, 1580-1588. [CrossRef] [PubMed]

30. Nemoto, N.; Suzukawa, K.; Shimizu, S.; Shinagawa, A.; Takei, N.; Taki, T.; Hayashi, Y.; Kojima, H.; Kawakami, Y.; Nagasawa, T. Identification of a novel fusion geneMLL-MAML2 in secondary acute myelogenous leukemia and myelodysplastic syndrome with inv(11)(q21q23). Genes Chromosom. Cancer 2007, 46, 813-819. [CrossRef] [PubMed]

31. Chu, Y.; Chen, Y.; Li, M.; Shi, D.; Wang, B.; Lian, Y.; Cheng, X.; Wang, X.; Xu, M.; Cheng, T.; et al. Six1 regulates leukemia stem cell maintenance in acute myeloid leukemia. Cancer Sci. 2019, 110, 2200-2210. [CrossRef]

32. Barclay, A.N.; Brown, M.H. The SIRP family of receptors and immune regulation. Nat. Rev. Immunol. 2006, 6, 457-464. [CrossRef] [PubMed]

33. Otten, J.; Schmitz, L.; Vettorazzi, E.; Schultze, A.; Marx, A.H.; Simon, R.; Krauter, J.; Loges, S.; Sauter, G.; Bokemeyer, C.; et al. Expression of TGF- $\beta$ receptor ALK-5 has a negative impact on outcome of patients with acute myeloid leukemia. Leukemia 2010, 25, 375-379. [CrossRef]

34. Papayannopoulou, T.; Nakamoto, B.; Kurachi, S.; Tweeddale, M.; Messner, H. Surface antigenic profile and globin phenotype of two new human erythroleukemia lines: Characterization and interpretations. Blood 1988, 72, 1029-1038. [CrossRef]

35. Moriguchi, T.; Yamamoto, M. A regulatory network governing Gata1 and Gata2 gene transcription orchestrates erythroid lineage differentiation. Int. J. Hematol. 2014, 100, 417-424. [CrossRef] [PubMed]

36. Starck, J.; Weiss-Gayet, M.; Gonnet, C.; Guyot, B.; Vicat, J.M.; Morlé, F. Inducible Fli-1 gene deletion in adult mice modifies several myeloid lineage commitment decisions and accelerates proliferation arrest and terminal erythrocytic differen-tiation. Blood 2010, 116, 4795-4805. [CrossRef]

37. Mouthon, M.A.; Freund, M.; Titeux, M.; Katz, A.; Guichard, J.; Breton-Gorius, J.; Vainchenker, W. Growth and differentiation of the human megakaryoblastic cell line (ELF-153): A model for early stages of megakaryocytopoiesis. Blood 1994, 84, $1085-1097$. [CrossRef]

38. Szalai, G.; LaRue, A.C.; Watson, D.K. Molecular mechanisms of megakaryopoiesis. Cell. Mol. Life Sci. 2006, 63, 2460-2476. [CrossRef]

39. Creed, T.M.; Baldeosingh, R.; Eberly, C.L.; Schlee, C.S.; Kim, M.; Cutler, J.A.; Pandey, A.; Civin, C.I.; Fossett, N.G.; Kingsbury, T.J. PAX-SIX-EYA-DACH Network modulates GATA-FOG function in fly hematopoiesis and human erythropoiesis. Development 2020, 147, dev177022. [CrossRef]

40. Maharana, S.K.; Schlosser, G. A gene regulatory network underlying the formation of pre-placodal ectoderm in Xenopus laevis. BMC Biol. 2018, 16, 79. [CrossRef]

41. Becker, H.; Marcucci, G.; Maharry, K.; Radmacher, M.D.; Mrózek, K.; Margeson, D.; Whitman, S.P.; Wu, Y.Z.; Schwind, S.; Paschka, P.; et al. Favorable prognostic impact of NPM1 mutations in older patients with cytogenetically normal de novo acute myeloid leukemia and associated gene- and microRNA-expression signatures: A Cancer and leukemia group B study. J. Clin. Oncol. 2010, 28, 596-604. [CrossRef]

42. Dovey, O.M.; Cooper, J.L.; Mupo, A.; Grove, C.S.; Lynn, C.; Conte, N.; Andrews, R.M.; Pacharne, S.; Tzelepis, K.; Vijayabaskar, M.S.; et al. Molecular synergy underlies the co-occurrence patterns and phenotype of NPM1-mutant acute myeloid leukemia. Blood 2017, 130, 1911-1922. [CrossRef] [PubMed] 
43. Al Hinai, A.S.; Pratcorona, M.; Grob, T.; Kavelaars, F.G.; Bussaglia, E.; Sanders, M.A.; Nomdedeu, J.; Valk, P.J. The Landscape of KMT2A-PTD AML: Concurrent Mutations, Gene Expression Signatures, and Clinical Outcome. HemaSphere 2019,3 , e181. [CrossRef] [PubMed]

44. Kang, H.; Sharma, N.D.; Nickl, C.K.; Devidas, M.; Loh, M.L.; Hunger, S.P.; Dunsmore, K.P.; Winter, S.S.; Matlawska-Wasowska, K. Dysregulated transcriptional networks in KMT2A- and MLLT10-rearranged T-ALL. Biomark. Res. 2018, 6, 27. [CrossRef]

45. Garcia-Cuellar, M.-P.; Büttner, C.; Bartenhagen, C.; Dugas, M.; Slany, R.K. Leukemogenic MLL-ENL Fusions Induce Alternative Chromatin States to Drive a Functionally Dichotomous Group of Target Genes. Cell Rep. 2016, 15, 310-322. [CrossRef] [PubMed]

46. Le Noir, S.; Ben Abdelali, R.; Lelorch, M.; Bergeron, J.; Sungalee, S.; Payet-Bornet, D.; Villarèse, P.; Petit, A.; Callens, C.; Lhermitte, L.; et al. Extensive molecular mapping of TCR $\alpha / \delta$ - and TCR $\beta$-involved chromosomal translocations reveals distinct mechanisms of oncogene activation in T-ALL. Blood 2012, 120, 3298-3309. [CrossRef]

47. Salanga, M.; Meadows, S.M.; Myers, C.T.; Krieg, P.A. ETS family protein ETV2 is required for initiation of the endothelial lineage but not the hematopoietic lineage in the Xenopus embryo. Dev. Dyn. 2010, 239, 1178-1187. [CrossRef]

48. Glenn, N.O.; Schumacher, J.A.; Kim, H.J.; Zhao, E.J.; Skerniskyte, J.; Sumanas, S. Distinct regulation of the anterior and posterior myeloperoxidase expression by Etv2 and Gata1 during primitive Granulopoiesis in zebrafish. Dev. Biol. 2014, 393, 149-159. [CrossRef]

49. Ferdous, A.; Caprioli, A.; Iacovino, M.; Martin, C.M.; Morris, J.; Richardson, J.A.; Latif, S.; Hammer, R.E.; Harvey, R.P.; Olson, E.N.; et al. Nkx2-5 transactivates theEts-related protein 71gene and specifies an endothelial/endocardial fate in the developing embryo. Proc. Natl. Acad. Sci. USA 2009, 106, 814-819. [CrossRef] [PubMed]

50. Watanabe, Y.; Seya, D.; Ihara, D.; Ishii, S.; Uemoto, T.; Kubo, A.; Arai, Y.; Isomoto, Y.; Nakano, A.; Abe, T.; et al. Importance of endothelial Hey1 expression for thoracic great vessel development and its distal enhancer for Notch-dependent endothelial transcription. J. Biol. Chem. 2020, 295, 17632-17645. [CrossRef]

51. Lilly, A.J.; Costa, G.; Largeot, A.; Fadlullah, M.Z.H.; Lie-A.-Ling, M.; Lacaud, G.; Kouskoff, V. Interplay between SOX7 and RUNX1 regulates hemogenic endothelial fate in the yolk sac. Development 2016, 143, 4341-4351. [CrossRef]

52. Cigudosa, J.C.; Odero, M.D.; Calasanz, M.J.; Solé, F.; Salido, M.; Arranz, E.; Martínez-Ramirez, A.; Urioste, M.; Alvarez, S.; Cervera, J.V.; et al. De novo erythroleukemia chromosome features include multiple re-arrangements, with special involvement of chromosomes 11 and 19. Genes Chromosom. Cancer 2003, 36, 406-412. [CrossRef] [PubMed]

53. Li, Y.; Luo, H.; Liu, T.; Zacksenhaus, E.; Ben-David, Y. The ets transcription factor Fli-1 in development, cancer and disease. Oncogene 2015, 34, 2022-2031. [CrossRef]

54. Xu, J.; Shao, Z.; Glass, K.; Bauer, D.E.; Pinello, L.; Van Handel, B.; Hou, S.; Stamatoyannopoulos, J.A.; Mikkola, H.K.; Yuan, G.-C.; et al. Combinatorial Assembly of Developmental Stage-Specific Enhancers Controls Gene Expression Programs during Human Erythropoiesis. Dev. Cell 2012, 23, 796-811. [CrossRef] [PubMed]

55. Seiffert, M.; Cant, C.; Chen, Z.; Rappold, I.; Brugger, W.; Kanz, L.; Brown, E.J.; Ullrich, A.; Bühring, H.J. Human signal-regulatory protein is expressed on normal, but not on subsets of leukemic myeloid cells and mediates cellular adhesion involving its counterreceptor CD47. Blood 1999, 94, 3633-3643. [CrossRef]

56. Nagel, S.; Meyer, C.; Kaufmann, M.; Drexler, H.G.; MacLeod, R.A. Aberrant expression of homeobox gene SIX1 in Hodgkin lymphoma. Oncotarget 2015, 6, 40112-40126. [CrossRef] [PubMed]

57. Zhang, L.-S.; Kang, X.; Lu, J.; Zhang, Y.; Wu, X.; Wu, G.; Zheng, J.; Tuladhar, R.; Shi, H.; Wang, Q.; et al. Installation of a cancer promoting WNT/SIX1 signaling axis by the oncofusion protein MLL-AF9. EBioMedicine 2019, 39, 145-158. [CrossRef]

58. Trinh, B.Q.; Barengo, N.; Kim, S.B.; Lee, J.S.; Zweidler-McKay, P.A.; Naora, H. The homeobox gene DLX4 regulates erythromegakaryocytic differentiation by stimulating IL-1 $\beta$ and NF-кB signaling. J. Cell Sci. 2015, 128, 3055-3067.

59. Quentmeier, H.; Pommerenke, C.; Dirks, W.G.; Eberth, S.; Koeppel, M.; MacLeod, R.A.F.; Nagel, S.; Steube, K.; Uphoff, C.C.; Drexler, H.G. The LL-100 panel: 100 cell lines for blood cancer studies. Sci. Rep. 2019, 9, 8218. [CrossRef]

60. Casero, D.; Sandoval, S.; Seet, C.S.; Scholes, J.; Zhu, Y.; Ha, V.L.; Luong, A.; Parekh, C.; Crooks, G.M. Long non-coding RNA profil-ing of human lymphoid progenitor cells reveals transcriptional divergence of B cell and T cell lineages. Nat. Immunol. 2015, 16, 1282-1291. [CrossRef] [PubMed]

61. Rapin, N.; Bagger, F.O.; Jendholm, J.; Mora-Jensen, H.; Krogh, A.; Kohlmann, A.; Thiede, C.; Borregaard, N.; Bullinger, L.; Winther, O.; et al. Comparing cancer vs normal gene expression profiles identifies new disease entities and common transcriptional programs in AML patients. Blood 2014, 123, 894-904. [CrossRef] [PubMed]

62. Klein, H.U.; Ruckert, C.; Kohlmann, A.; Bullinger, L.; Thiede, C.; Haferlach, T.; Dugas, M. Quantitative comparison of microar-ray experiments with published leukemia related gene expression signatures. BMC Bioinform. 2009, 10, 422. [CrossRef] [PubMed]

63. Bagger, F.O.; Sasivarevic, D.; Sohi, S.H.; Laursen, L.G.; Pundhir, S.; Sønderby, C.K.; Winther, O.; Rapin, N.; Porse, B.T. BloodSpot: A database of gene expression profiles and transcriptional programs for healthy and malignant haematopoiesis. Nucleic Acids Res. 2016, 44, D917-D924. [CrossRef] [PubMed]

64. Huang, D.W.; Sherman, B.T.; Tan, Q.; Collins, J.R.; Alvord, W.G.; Roayaei, J.; Stephens, R.; Baseler, M.W.; Lane, H.C.; Lempicki, R.A. DAVID Gene functional classification tool: A novel biological module-centric algorithm to functionally analyze large gene list. Genome Biol. 2007, 8, R183. [CrossRef] [PubMed]

65. Drexler, H.G. Guide to Leukemia-Lymphoma Cell Lines, 2nd ed.; DSMZ: Braunschweig, Germany, 2010.

66. MacLeod, R.A.F.; Kaufmann, M.E.; Drexler, H.G. Cytogenetic Harvesting of Cancer Cells and Cell Lines. Methods Mol. Biol. 2016, 1541, 43-58. [CrossRef] 